\title{
Patient characteristics, resource use and outcomes associated with general internal medicine hospital care: the General Medicine Inpatient Initiative (GEMINI) retrospective cohort study
}

\author{
Amol A. Verma MD MPhil, Yishan Guo MSc, Janice L. Kwan MD MPH, Lauren Lapointe-Shaw MD, \\ Shail Rawal MD MPH, Terence Tang MD, Adina Weinerman MD MHSc, Peter Cram MD MBA, \\ Irfan A. Dhalla MD MSc, Stephen W. Hwang MD MPH, Andreas Laupacis MD MSc, \\ Muhammad M. Mamdani PharmD MPH, Steven Shadowitz MDCM MSc, Ross Upshur MD MSc, \\ Robert J. Reid MD PhD, Fahad Razak MD MSc
}

\section{Abstract}

Background: The precise scope of hospital care delivered under general internal medicine services remains poorly quantified. The purpose of this study was to describe the demographic characteristics, medical conditions, health outcomes and resource use of patients admitted to general internal medicine at 7 hospital sites in the Greater Toronto Area.

Methods: This was a retrospective cohort study involving all patients who were admitted to or discharged from general internal medicine at the study sites between Apr. 1, 2010, and Mar. 31, 2015. Clinical data from hospital electronic information systems were linked to administrative data from each hospital. We examined trends in resource use and patient characteristics over the study period.

Results: There were 136208 admissions to general internal medicine involving 88121 unique patients over the study period. General internal medicine admissions accounted for $38.8 \%$ of all admissions from the emergency department and $23.7 \%$ of all hospital bed-days. Over the study period, the number of admissions to general internal medicine increased by $32.4 \%$; there was no meaningful change in the median length of stay or cost per hospital stay. The median patient age was 73 (interquartile range [IQR] 57-84) years, and the median number of coexisting conditions was 6 (IQR 3-9). The median acute length of stay was 4.6 (IQR 2.5-8.6) days, and the median total cost per hospital stay was \$5850 (IQR \$3915-\$10 061). Patients received at least 1 computed tomography scan in $52.2 \%$ of admissions. The most common primary discharge diagnoses were pneumonia (5.0\% of admissions), heart failure $(4.7 \%)$, chronic obstructive pulmonary disease $(4.1 \%)$, urinary tract infection $(4.0 \%)$ and stroke $(3.6 \%)$.

Interpretation: Patients admitted to general internal medicine services represent a large, heterogeneous, resource-intensive and growing population. Understanding and improving general internal medicine care is essential to promote a high-quality, sustainable health care system.

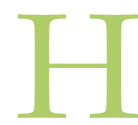
ospital care accounts for $30 \%$ of health care expenditure in Canada, making it the largest contributor to health care costs. ${ }^{1}$ There has been a welldescribed growth in inpatient medical care by hospitalist physicians, ${ }^{2}$ most of whom are not subspecialists but, rather, general internists and family physicians. ${ }^{3}$ This care is often delivered under a general internal medicine service. An aging population and a growing number of patients with multiple chronic conditions ${ }^{4,5}$ have resulted in more inpatients whose care falls outside clearly delineated subspecialty areas. Relatively little research has focused on the characteristics of general internal medicine inpatients or the quality of care that they receive. To our knowledge, the proportion of hospital resources devoted to these patients in Canada has not been reported. Studies examining medical care in hospital typically include all medical admissions regardless of whether patients are cared for by a general or subspecialty

Competing interests: See the end of the article.

This article has been peer reviewed.

Correspondence to: Amol Verma, amol.verma@mail.utoronto.ca; Fahad Razak, fahad.razak@mail.utoronto.ca

CMAJ Open 2017. DOI:10.9778/cmajo.20170097 
service $^{6,7}$ or include only patients with specific diseases, such as heart failure, myocardial infarction or pneumonia. ${ }^{8}$

Thus, the precise scope of hospital care delivered under general internal medicine services remains poorly quantified. Given that these services likely care for a large and growing inpatient population, the purpose of this study was to characterize general internal medicine inpatients with respect to demographic characteristics, medical conditions, health outcomes and resource use at 7 hospital sites in the Greater Toronto Area.

\section{Methods}

\section{Design and setting}

The General Medicine Inpatient Initiative (GEMINI) study is a retrospective cohort study involving 7 large hospital sites at 5 health care organizations affiliated with the University of Toronto serving adults in the Greater Toronto Area. Participating sites are St. Michael's Hospital, Sinai Health System (Mount Sinai Hospital), Sunnybrook Health Sciences Centre, Trillium Health Partners (Credit Valley and Mississauga sites) and the University Health Network (Toronto General Hospital and Toronto Western Hospital). Trillium Health Partners is a large community teaching hospital serving the neighbouring city of Mississauga (population 756000 ). ${ }^{9}$ The remaining GEMINI hospitals are academic health centres in Toronto (population 2790 000)..$^{10}$ Each health care organization participating in GEMINI is independent, with distinct governance, funding, administration, staff and information technology systems. Medical students and residents from the University of Toronto rotate between the various GEMINI hospitals.

\section{Participants}

The GEMINI cohort included all patients who were admitted to or discharged from the general internal medicine service at 1 of the 7 hospitals between Apr. 1, 2010, and Mar. 31, 2015 (further details described in Supplemental Methods 1, Appendix 1, available at www.cmajopen.ca/content/5/4/E842/suppl/ DC1). Based on these inclusion criteria, patients who were transiently cared for by the general internal medicine service but were admitted to and discharged by another hospital service were not included in the cohort. There were no exclusion criteria.

The general internal medicine service includes hospitalist services as well as clinical teaching units that are approved by the Royal College of Physicians and Surgeons of Canada and involve undergraduate and postgraduate medical trainees (Supplemental Methods 2, Appendix 1). Across the participating sites, there were 283 attending physicians in general internal medicine, $92.6 \%$ of whom were general internists or internal medicine subspecialists and $7.4 \%$ of whom were family physicians.

\section{Data collection}

At the individual patient level, we linked administrative health data with clinical data that were extracted from hospital infor- mation systems (Supplemental Figure 1, Appendix 1). Data were collected locally at each hospital, de-identified and transferred to St. Michael's Hospital, where they were stored securely on firewall-protected hospital servers. We used a secure hash algorithm using patient health insurance number to track de-identified patients across sites. ${ }^{11,12}$

\section{Administrative health data}

We collected patient-level characteristics including demographic characteristics, diagnoses, interventions, discharge destination and resource use as reported by participating hospitals to the Canadian Institute for Health Information (CIHI) Discharge Abstract Database and National Ambulatory Care Reporting System. These 2 databases contain these data for all hospital discharges and emergency department encounters, respectively. Data regarding diagnoses and interventions are coded manually by hospital-based chart abstractors using the enhanced Canadian version of the 10th revision of the International Statistical Classification of Diseases and Related Health Problems (ICD-10-CA) and the Canadian Classification of Health Interventions. Data from the CIHI have formed the basis for a substantial body of clinical and health services research. ${ }^{13-15}$ We also obtained data about overall hospital patient volumes and bed use from the decision support department of each hospital.

\section{Electronic clinical data}

We collected data from the electronic information systems at each hospital about in-hospital patient room transfers, laboratory (biochemistry, hematology and microbiology) test results, blood transfusions, radiology test results, in-hospital medications, dietary orders, vital signs and routine clinical monitoring. The data elements that could be extracted from each site are described in Supplemental Table 1, Appendix 1.

Data were extracted at each hospital into comma-separated values files. To allow for site-specific differences in data extraction and results formats, we provided an ideal data format and table structure to each hospital to populate. Where possible, standardized data elements were used, such as Drug Identification Number for pharmacy data. Where existing standards were not uniformly applied, for example with laboratory data, the available data were extracted at each site and centrally mapped to a common format.

Data extracted from electronic clinical records have been used in large, high-quality research studies. ${ }^{16,17}$ To assess the quality of the extracted electronic clinical data from each hospital, we performed visual checks for each type of data (e.g., laboratory, radiology) to examine the number of tests and treatments performed and the number of missing values. First, we examined these over the study duration to ensure that there were no clusters of missingness or patterns that might represent extraction problems. Second, we examined the data separately for both the emergency department and inpatient portion of the hospital stay to ensure that there were no errors in data linkage across different portions of hospital encounters. 


\section{Measures}

We described demographic characteristics, coexisting medical conditions, patient outcomes and resource use among all admissions to general internal medicine and for each of the most prevalent discharge diagnoses. To examine coexisting conditions, we used 3-character ICD-10-CA codes from the CIHI Discharge Abstract Database for each admission. We calculated both a simple count of all coexisting conditions and the revised Charlson Comorbidity Index score. ${ }^{18}$ To describe patient outcomes, we reported use of the intensive care unit, in-hospital death and readmission to general internal medicine at 1 of the GEMINI hospitals within 30 days of discharge.

We calculated acute inpatient length of stay by subtracting the number of days spent at an alternate level of care from total hospital length of stay. Alternate level of care is a designation for patients who no longer require acute care but are awaiting transfer to a different care level, such as a rehabilitation facility. We also considered transfer to inpatient palliative care within the same facility as discharge from acute care.

To estimate hospital stay costs such that they could be compared across study sites and years, we used the CIHI Resource Intensity Weight for each admission using the 2015 grouping methodology ${ }^{19}$ and multiplied this by the annual cost per weighted case for acute inpatient cases that was reported for each hospital using the Ontario Cost Distribution Methodology. ${ }^{20}$ This approach estimates the average amount of hospital resources used for each hospital stay, including costs related to administration, staff, supplies, technology and equipment. It does not include fee-for-service physician billing costs.

We used electronic clinical data to describe the proportion of patients who received at least 1 of each imaging test (radiography, computed tomography, ultrasonography, magnetic resonance imaging), interventional radiology procedure (defined as any procedure performed by the radiology department) or erythrocyte transfusion. We used Canadian Classification of Health Interventions codes to describe the number of patients receiving dialysis, endoscopy or bronchoscopy.

To determine the proportion of hospital resources that were used by general internal medicine patients, we compared the number of hospital admissions, admissions to hospital from the emergency department (which we refer to as "emergency admissions") and total bed-days for patients in the GEMINI cohort to overall hospital values (Supplemental Methods 3, Appendix 1).

We identified the most prevalent primary discharge diagnoses in general internal medicine using the $2015 \mathrm{CIHI}$ casemix groups. Every acute inpatient discharge is classified into a single case-mix group through the CIHI CMG+ methodology, which is based on the most responsible diagnosis and interventions received in hospital. ${ }^{21}$ Because there are different methods of categorizing ICD-10-CA codes into clinically similar conditions, we tested the validity of our findings by comparing the sensitivity and specificity of the CIHI case-mix groups against existing cohort definitions for the 5 most prevalent conditions. ${ }^{22-27}$

We described changes in resource use in general internal medicine over the study period by examining the annual number of hospital admissions, the proportion of total hospital admissions that were general internal medicine admissions, median cost, median acute length of stay, rate of 30-day readmission to general internal medicine within the hospitals and use of advanced imaging (proportion of patients who received at least 1 computed tomography scan, magnetic resonance imaging scan or ultrasound test). We also described changes in basic patient characteristics (age, sex, comorbidity score and number of coexisting medical conditions) over the study period.

\section{Statistical analysis}

Simple descriptive statistics are presented for all findings because we made no prespecified hypotheses. Owing to skewed distributions, we summarized variables using median and interquartile range (IQR). We performed all analyses using $\mathrm{R}$ version 3.3.2 ( $\mathrm{R}$ Foundation).

\section{Ethics approval}

Research ethics board approval was obtained from all participating hospitals. Waivers of informed consent were obtained because this was a large retrospective study with minimal risk.

\section{Results}

\section{Demographic characteristics and coexisting medical conditions}

There were 136208 admissions to general internal medicine services involving 88121 unique patients between Apr. 1, 2010, and Mar. 31, 2015 (Table 1). There were 1678 hospital admissions with no health insurance number. They could not be tracked across sites, and each was considered a unique patient. The study population was $50.6 \%$ women, and the median age was 73 (IQR 57-84) years. Patients aged less than 60 years accounted for $28.6 \%$ of the admissions, and those older than 80 years, for $37.6 \%$ (Supplemental Figure 2, Appendix 1).

Patients had a median of 6 (IQR 3-9) coexisting conditions per hospital stay. Roughly the same proportions of admissions were associated with high (Charlson Comorbidity Index score $\geq 2$ ) and low (score of 0 ) degrees of comorbidity (57 331 [42.1\%] and 58257 [42.8\%], respectively). Hypertension (51 204 admissions [37.6\%]) and type 2 diabetes mellitus (45 $376[33.3 \%]$ ) were the most prevalent comorbid conditions (Table 1).

\section{Patient outcomes and resource use}

Admissions to general internal medicine accounted for 17.4\% of all hospital admissions, $38.8 \%$ of all emergency admissions and $23.7 \%$ of all hospital bed-days. Of all the admissions to general internal medicine, $9.9 \%$ involved admission to an intensive care unit, $6.5 \%$ resulted in death in hospital, and 


\begin{tabular}{|c|c|}
\hline \multicolumn{2}{|c|}{$\begin{array}{l}\text { Table 1: Characteristics of hospital admissions in the } \\
\text { General Medicine Inpatient Initiative study cohort }\end{array}$} \\
\hline Characteristic & $\begin{array}{c}\text { No. (\%) of } \\
\text { admissions }^{*} \\
n=136208\end{array}$ \\
\hline Age, median (IQR), yr & $73(57-84)$ \\
\hline \multicolumn{2}{|l|}{ Age group, yr } \\
\hline$<60$ & $39004(28.6)$ \\
\hline $60-80$ & 46039 (33.8) \\
\hline$>80$ & $51165(37.6)$ \\
\hline Female sex & $68971(50.6)$ \\
\hline No. of comorbidities, median (IQR) & $6(3-9)$ \\
\hline \multicolumn{2}{|l|}{ Charlson Comorbidity Index score } \\
\hline 0 & $58257(42.8)$ \\
\hline 1 & $20620(15.1)$ \\
\hline$\geq 2$ & $57331(42.1)$ \\
\hline \multicolumn{2}{|l|}{ Most common comorbid conditions } \\
\hline Hypertension & $51204(37.6)$ \\
\hline Type 2 diabetes mellitus & $45376(33.3)$ \\
\hline Atrial fibrillation and flutter & $19947(14.6)$ \\
\hline Dyslipidemia & $19518(14.3)$ \\
\hline Electrolyte abnormality & $19113(14.0)$ \\
\hline Heart failure & $18736(13.8)$ \\
\hline \multicolumn{2}{|l|}{ Discharge disposition } \\
\hline Home & $96414(70.8)$ \\
\hline Nursing home or rehabilitation facility & $25804(18.9)$ \\
\hline Death & $8916(6.5)$ \\
\hline Discharge against medical advice & $2543(1.9)$ \\
\hline Other acute care hospital & $1841(1.4)$ \\
\hline Other & $690(0.5)$ \\
\hline $\begin{array}{l}\text { Note: IQR = interquartile range. } \\
\text { "Except where noted otherwise. }\end{array}$ & \\
\hline
\end{tabular}

$10.9 \%$ resulted in readmission to general internal medicine at 1 of the study hospitals within 30 days of discharge (Table 2). The median total cost per hospital stay was \$5850 (IQR \$3915-\$10 061) (Table 3). The median acute length of stay was 4.6 (IQR 2.5-8.6) days. Patients were designated alternate level of care in $12.4 \%$ of admissions, and alternate level of care days represented $22.0 \%$ of all general internal medicine bed-days. At hospital discharge, 96414 patients [70.8\%]) returned home, and 25804 (18.9\%) were transferred to a nursing home or rehabilitation facility (Table 1 ).

Patients received at least 1 computed tomography scan in just over half of admissions (53 125 [52.2\%]), ultrasound examination in 28893 (28.4\%), magnetic resonance imaging scan in $11649(11.4 \%)$, interventional radiology procedure in $10778(10.6 \%)$, erythrocyte transfusion in $9325(9.2 \%)$, endoscopy or bronchoscopy in 13832 (10.2\%) and dialysis in 2448 (1.8\%) (Table 4).

\section{Time trends in resource use and patient characteristics}

The number of admissions to general internal medicine increased by $32.4 \%$ over the study period, from 23475 in 2010/11 to 31078 in 2014/15 (Figure 1). The proportion of all inpatients cared for by general internal medicine increased by $10.4 \%$ to $28.7 \%$ over the study period at every hospital except for 1 , where it decreased by $19.9 \%$. There was no meaningful change over time in the median acute length of stay (4.6 d in both the first and last study year) or median cost (\$5808-\$5813). There was a small increase in 30-day readmission to general internal medicine, from $10.5 \%$ to $11.3 \%$, and there was a reduction in the proportion of patients who received at least 1 advanced imaging test (ultrasound examination, computed tomography scan or magnetic resonance imaging scan), from $66.9 \%$ to $63.3 \%$. There was no meaningful change in patient age, sex, comorbidity score or number of coexisting medical conditions over the study duration (Supplemental Table 2, Appendix 1).

\section{Prevalent discharge diagnoses}

The most common discharge case-mix groups were pneumonia $(5.0 \%)$, heart failure $(4.7 \%)$, chronic obstructive pulmonary disease $(4.1 \%)$, urinary tract infection $(4.0 \%)$ and stroke not including transient ischemic attack (3.6\%). Compared with other cohort definitions, the specificity of the CIHI casemix groups for all of these conditions was greater than $99.9 \%$, and the sensitivity ranged from $80.4 \%$ to $99.2 \%$ (Supplemental Table 3, Appendix 1).

\section{Characteristics of most common case-mix groups}

Patient characteristics, outcomes and resource use for the most common conditions are presented in Table 2, Table 3 and Table 4. There were high levels of multimorbidity among patients with all of the most prevalent diagnoses, with a median of 5-7 (IQR 3-10) coexisting conditions. Intensive care unit use and death in hospital were highest among patients with stroke $(14.5 \%$ and $8.3 \%$, respectively, of admissions) and lowest among patients with urinary tract infection (5.3\% and $2.7 \%$, respectively). Patients with chronic obstructive pulmonary disease had high levels of intensive care unit use $(12.6 \%)$ but relatively lower rates of death $(5.2 \%)$.

Patients with stroke had the highest rates of being designated alternate level of care (24.4\% of admissions), the longest median acute length of stay (6.4 [IQR 3.9-10.4] d) and the highest median cost per hospital stay (\$6915 [IQR \$5584$\$ 11455])$. There was marked variation in patient age, comorbidity, length of stay and cost among the most common diagnoses (Table 2, Table 3).

\section{Interpretation}

In this study of more than 136000 hospital admissions at 5 academic and 2 community hospital sites in the Greater Toronto Area, admissions to general internal medicine accounted for $38.8 \%$ of emergency admissions and $23.7 \%$ of all hospital bed-days, and the number of general internal 
Table 2: Characteristics of hospital admissions and outcomes among most prevalent conditions in general internal medicine*

\begin{tabular}{|c|c|c|c|c|c|c|}
\hline \multirow[b]{2}{*}{ Characteristic } & \multicolumn{6}{|c|}{ Condition; no. (\%) of admissions $†$} \\
\hline & $\begin{array}{l}\text { Total cohort } \\
n=136208\end{array}$ & $\begin{array}{c}\text { Pneumonia } \\
n=6804\end{array}$ & $\begin{array}{c}\text { Heart failure } \\
n=6341\end{array}$ & $\begin{array}{l}\text { Chronic } \\
\text { obstructive } \\
\text { pulmonary } \\
\text { disease } \\
n=5574\end{array}$ & $\begin{array}{l}\text { Urinary tract } \\
\text { infection } \\
n=5466\end{array}$ & $\begin{array}{c}\text { Stroke } \\
n=4912\end{array}$ \\
\hline Age, median (IQR), yr & $73(57-84)$ & $80(64-87)$ & $83(75-88)$ & $77(66-84)$ & $80(69-87)$ & $76(64-84)$ \\
\hline Comorbidities, median (IQR) & $6(3-9)$ & $5(3-8)$ & $7(5-10)$ & $6(3-8)$ & $6(4-9)$ & $5(3-7)$ \\
\hline Intensive care unit use $\ddagger$ & $10031(9.9)$ & $460(8.6)$ & $409(8.0)$ & $589(12.6)$ & $185(5.3)$ & $337(14.5)$ \\
\hline Death in hospital & $8916(6.5)$ & $534(7.8)$ & $491(7.7)$ & $293(5.3)$ & $150(2.7)$ & $410(8.3)$ \\
\hline 30-day readmission§ & $14387(10.9)$ & $620(9.4)$ & $990(16.1)$ & $893(16.5)$ & $663(12.4)$ & $268(5.7)$ \\
\hline \multicolumn{7}{|c|}{$\begin{array}{l}\text { Note: IQR = interquartile range. } \\
\text { *Identified with the use of Canadian Institute for Health Information case-mix groups. } \\
\text { †Except where noted otherwise. } \\
\text { †Intensive care or step-up unit. Does not include data for } 34453 \text { patients at Trillium Health Partners (data not available at the time of submission). } \\
\text { §Readmission to general internal medicine service at } 1 \text { of the participating hospitals within } 30 \text { days of discharge. Patients with no health insurance number could not be } \\
\text { linked across admissions and were excluded from this calculation, as were patients discharged within the last } 30 \text { days of the study. }\end{array}$} \\
\hline
\end{tabular}

Table 3: Resource use among most prevalent conditions in general internal medicine

\begin{tabular}{|c|c|c|c|c|c|c|}
\hline Cost, median (IQR), $\$^{*}$ & $\begin{array}{c}5850 \\
(3915-10061)\end{array}$ & $\begin{array}{c}5935 \\
(4343-8068)\end{array}$ & $\begin{array}{c}6706 \\
(4956-9403)\end{array}$ & $\begin{array}{c}6148 \\
(4459-8741)\end{array}$ & $\begin{array}{c}5391 \\
(3981-7140)\end{array}$ & $\begin{array}{c}6915 \\
(5584-11455)\end{array}$ \\
\hline $\begin{array}{l}\text { Length of stay, median } \\
\text { (IQR), d }\end{array}$ & $4.6(2.5-8.6)$ & $4.5(2.5-7.7)$ & $5.6(3.1-9.7)$ & $4.4(2.5-7.5)$ & $4.4(2.7-6.9)$ & $6.4(3.9-10.4)$ \\
\hline $\begin{array}{l}\text { Bed-days, no. (\% of total } \\
\text { for cohort) }\end{array}$ & 1310717 (100.0) & $50059(3.8)$ & $56799(4.3)$ & $39159(3.0)$ & $39552(3.0)$ & 64550 (4.9) \\
\hline $\begin{array}{l}\text { Alternate level of care } \\
\text { designation, no. (\%) of } \\
\text { admissions }\end{array}$ & $16868(12.4)$ & 567 (8.3) & $614(9.7)$ & $434(7.8)$ & $609(11.1)$ & $1197(24.4)$ \\
\hline $\begin{array}{l}\text { Alternate level of care } \\
\text { days, no. (\% of total } \\
\text { alternate level of care } \\
\text { days) }\end{array}$ & $288250(100.0)$ & $6713(2.3)$ & $7585(2.6)$ & $4949(1.7)$ & $7531(2.6)$ & $19075(6.6)$ \\
\hline
\end{tabular}

medicine admissions grew by $32.4 \%$ between $2010 / 11$ and 2014/15. The most prevalent conditions in general internal medicine (chronic obstructive pulmonary disease, pneumonia, heart failure and stroke) are among the most costly causes of admission to hospital in Canada. ${ }^{28}$

Despite the substantially increased number of general internal medicine admissions and an increase in the proportion of inpatients cared for by general internal medicine at most sites over time, there was no meaningful change in the median cost of hospital stay or length of stay. There was a small increase in 30-day readmission to general internal medicine and a reduction in the proportion of patients who received advanced imaging tests. It appears that general internal medicine services have been able to accommodate increased volume without major changes in patient outcomes or resource use. There were no major changes in basic patient characteristics, and, thus, further work is needed to understand the drivers of changes in resource use over time.

Our findings are generally consistent with those of other studies conducted in general internal medicine patient populations. In 2 studies, both involving about 10000 patients at 7 teaching hospitals in Alberta, the most prevalent discharge diagnoses were chronic obstructive pulmonary disease, pneumonia, heart failure, urinary tract infection and venous thromboembolism, and the in-hospital death rate ranged from $3.9 \%$ to $7.4 \%$ across hospitals. 29,30 The median length of stay in our study was 4.6 days, similar to that in studies in the United States and Europe (4.0). ${ }^{31,32}$ Patients admitted to 
general internal medicine are often characterized as older and highly multimorbid; ${ }^{33}$ in our study, the median age was 73 years, and patients had a median of 6 coexisting conditions. However, one of our most striking findings was the marked heterogeneity of our patient population. Nearly 30\% were less than 60 years of age, and nearly $40 \%$ were more than 80 years. Forty-three percent had a low comorbidity score, whereas $42 \%$ had high comorbidity. There was dramatic vari-

\begin{tabular}{|c|c|c|c|c|c|c|}
\hline \multirow[b]{2}{*}{ Service } & \multicolumn{6}{|c|}{ Condition; no. (\%) of admissions ${ }^{*}$} \\
\hline & Total cohort & Pneumonia & Heart failure & $\begin{array}{l}\text { Chronic } \\
\text { obstructive } \\
\text { pulmonary } \\
\text { disease }\end{array}$ & $\begin{array}{l}\text { Urinary tract } \\
\text { infection }\end{array}$ & Stroke \\
\hline Radiography† & $84481(83.0)$ & $5242(98.5)$ & $5040(99.0)$ & $4592(98.5)$ & 3069 (87.7) & $1562(67.1)$ \\
\hline Computed tomography $\dagger$ & $53125(52.2)$ & $2327(43.7)$ & $1459(28.6)$ & $1571(33.7)$ & $1631(46.6)$ & $2265(97.3)$ \\
\hline Ultrasonography† & $28893(28.4)$ & $985(18.5)$ & $1606(31.5)$ & $777(16.7)$ & $1261(36.0)$ & $841(36.1)$ \\
\hline $\begin{array}{l}\text { Magnetic resonance } \\
\text { imagingt }\end{array}$ & $11649(11.4)$ & $118(2.2)$ & $72(1.4)$ & $55(1.2)$ & $131(3.7)$ & $1512(64.9)$ \\
\hline Interventional radiology† & $10778(10.6)$ & $259(4.9)$ & $201(3.9)$ & $141(3.0)$ & $322(9.2)$ & $150(6.4)$ \\
\hline Erythrocyte transfusion $\dagger$ & $9325(9.2)$ & $213(4.0)$ & $243(4.8)$ & $105(2.3)$ & $114(3.3)$ & $55(2.4)$ \\
\hline Endoscopy/bronchoscopy & $13832(10.2)$ & $360(5.3)$ & $169(2.7)$ & $182(3.3)$ & $101(1.8)$ & $139(2.8)$ \\
\hline Dialysis & $2448(1.8)$ & $130(1.9)$ & $91(1.4)$ & $44(0.8)$ & $41(0.8)$ & $36(0.7)$ \\
\hline
\end{tabular}

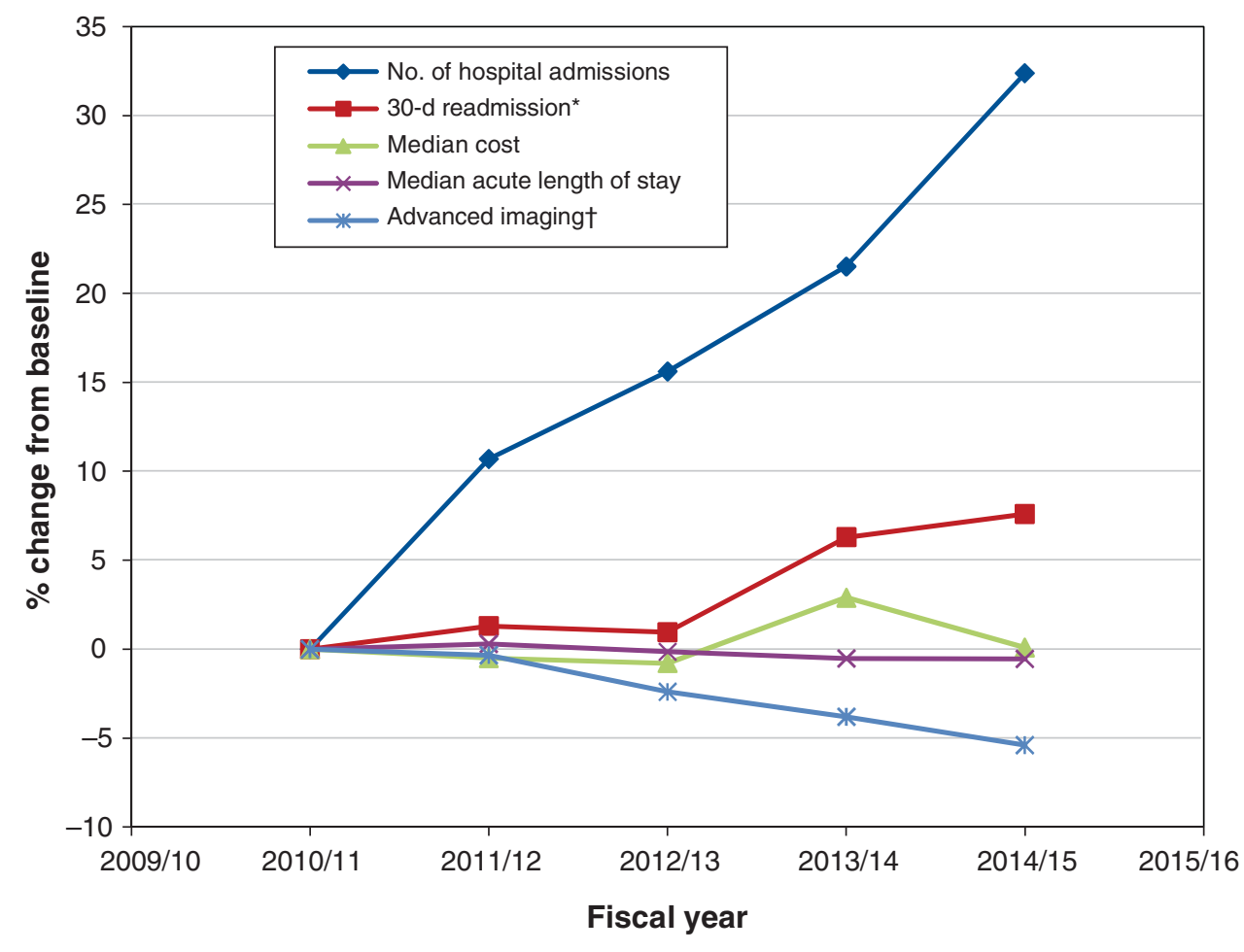

Figure 1: Trends in resource use in general internal medicine between Apr. 1, 2010, and Mar. 31, 2015. * Readmission to general internal medicine at 1 of the participating hospitals within 30 days of discharge. †Proportion of patients who received at least 1 ultrasound examination, computed tomography scan or magnetic resonance imaging scan, as an indicator of the intensity of investigations patients received. 
ability in length of stay and resource use among hospital stays for the same diagnosis. For example, the median length of stay for patients with heart failure was 5.6 days, but the 25 th and 75 th percentiles were 3.1 and 9.7 days, respectively. Thus, general internal medicine patients are highly variable in terms of individual characteristics, the conditions that lead to hospital admission, and resource use and outcomes within each condition. The reasons for variability should be a major focus of research for this patient population, which is poorly represented by averages or other measures of central tendency.

\section{Strengths and limitations}

Our study has several strengths. We identified patients cared for by general internal medicine services by collecting hospitallevel data. Studies using centrally collected administrative data often include patients cared for by both general medical services and subspecialists, or they identify patients with specific diagnoses and are thus unable to capture the true scope of general internal medicine. This is an important advantage of our study design, as general internal medicine wards are a functional unit for care delivery and represent an important target for quality-improvement initiatives. Our study also shows the feasibility of electronic data extraction across multiple hospitals, each with its own electronic medical record and information technology infrastructure. The marked heterogeneity of our patient population highlights the importance of comprehensively capturing a breadth of data for all patients as well as having a large sample. This was made possible in the current study through extraction of electronic clinical data.

One limitation of this study is the use of ICD-10-CA discharge diagnoses to define disease states. The CIHI databases require a single disease to be listed as the most responsible diagnosis. This presents an important limitation in cases in which conditions coexist or overlap, such as the comorbid complex of heart failure and pneumonia in patients presenting with dyspnea. Furthermore, the validity of our findings regarding resource use by discharge diagnosis are limited by the validity of the diagnostic codes. In reabstraction studies, the CIHI most responsible discharge diagnosis had excellent interrater agreement (93\%); ${ }^{34}$ validity for specific diagnoses is discussed in Supplemental Table 3 in Appendix 1. Second, we used only the diagnoses coded for each hospital admission to calculate the Charlson Comorbidity Index score, which may have underestimated the degree of comorbidity. Third, our study was conducted in 7 teaching hospitals in Canada's largest metropolitan area. Our patient sample is broadly similar to that in other studies in general internal medicine in Canada, the US and Europe, ${ }^{29-32}$ and our findings are likely generalizable to other urban and suburban academic health centres and large community hospitals, but the sample may not be representative of patients or practices in other settings. Fourth, we were able to capture readmission to general internal medicine only at hospitals within our network. We did not capture admissions to other medical services or hospitals outside the network. Admissions without a health insurance number $(1.2 \%)$ were excluded from this analysis because they could not be linked across visits. Thus, our analyses of readmission to general internal medicine underestimate all-cause readmission. Fifth, our analyses are reported at the level of hospital admissions. Given that we studied 136208 hospital admissions involving 88121 unique patients, patients with more than 1 admission may have disproportionately influenced our findings. In addition, chronic medical conditions that are more likely to result in readmission to hospital may have a greater prevalence in the current study than in analyses reported at the patient level. Finally, data collection was limited to elements that were readily available in electronic clinical data and administrative data. Thus, we were unable to report important information such as patient socioeconomic factors, functional status and frailty, caregiver support or advanced care planning. There is an opportunity for hospitals to standardize data collection around these factors, given their importance in determining patient outcomes.

\section{Conclusion}

Patients admitted to general internal medicine services represented a large and growing population that consumed substantial hospital resources. This population was characterized by marked heterogeneity, and there are substantial opportunities to develop measures of quality of care for general internal medicine patients, to study variations in care and outcomes, and to improve the quality of care. Electronic data collection and linkage can support multicentre research to study this complex population. Advancing our understanding of general internal medicine patients is essential for promoting a highquality, sustainable health care system.

\section{References}

1. National health expenditure trends, 1975 to 2016. Ottawa: Canadian Institute for Health Information; 2016.

2. Kuo YF, Sharma G, Freeman JL, et al. Growth in the care of older patients by hospitalists in the United States. N Engl 7 Med 2009;360:1102-12.

3. Soong C, Fan E, Howell EE, et al. Characteristics of hospitalists and hospitalist programs in the United States and Canada. 7 Clin Outcomes Manag 2009;16: 69-74.

4. Uijen AA, van de Lisdonk EH. Multimorbidity in primary care: prevalence and trend over the last 20 years. Eur 7 Gen Pract 2008;14:28-32.

5. Tinetti ME, Fried TR, Boyd CM. Designing health care for the most common chronic condition — multimorbidity. FAMA 2012;307:2493-4.

6. Tsugawa Y, Jha AK, Newhouse JP, et al. Variation in physician spending and association with patient outcomes. 7AMA Intern Med 2017;177:675-82.

7. Rifkin WD, Holmboe E, Scherer H, et al. Comparison of hospitalists and nonhospitalists in inpatient length of stay adjusting for patient and physician characteristics. 7 Gen Intern Med 2004;19:1127-32.

8. Dharmarajan K, Hsieh AF, Kulkarni VT, et al. Trajectories of risk after hospitalization for heart failure, acute myocardial infarction, or pneumonia: retrospective cohort study. BM7 2015;350:H411.

9. Mid-year population forecasts 2011 to 2031. Brampton (ON): Region of Peel. Available: www.peelregion.ca/planning/pdc/data/forecasts/population-2006 -2031.htm (accessed 2017 Jan. 8).

10. Toronto facts: diversity. Toronto: City of Toronto. Available: www1.toronto. $\mathrm{ca} / \mathrm{wps} /$ portal/contentonly? vgnextoid=dbe867b42d853410VgnVCM10000071 d60f89RCRD\&vgnextchannel=57a12cc817453410VgnVCM10000071d60f89 RCRD (accessed 2017 Jan. 8).

11. Dang QH. Secure hash standard. Vol. FIPS PUB 1, Federal Information Processing Standards Publication. Gaithersburg (MD): National Institute of Standards and Technology; 2015. Available: https://www.nist.gov/publications/ secure-hash-standard (accessed 2017 Dec. 4).

12. El Emam K. Guide to the de-identification of personal bealth information. Boca Raton (FL): CRC Press; 2013.

13. Gomes T, Martins D, Tadrous M, et al. Association of a blood glucose test strip quantity-limit policy with patient outcomes: a population-based study. 7AMA Intern Med 2017;177:61-6.

14. Filion KB, Azoulay L, Platt RW, et al. A multicenter observational study of incretin-based drugs and heart failure. N Engl f Med 2016;23:1145-54. 
15. Bekelman JE, Halpern SD, Blankart CR, et al. Comparison of site of death, health care utilization, and hospital expenditures for patients dying with cancer in 7 developed countries. FAMA 2016;315:272-83.

16. Curtis LH, Brown J, Platt R. Four health data networks illustrate the potential for a shared national multipurpose big-data network. Health Aff (Millwood) 2014;33:1178-86.

17. Rhee C, Dantes R, Epstein L, et al. Incidence and trends of sepsis in US hospitals using clinical vs claims data, 2009-2014. 7AMA 2017;2215:2009-14.

18. Quan H, Li B, Couris CM, et al. Updating and validating the Charlson Comorbidity Index and score for risk adjustment in hospital discharge abstracts using data from 6 countries. Am 7 Epidemiol 2011;173:676-82.

19. DAD resource intensity weights and expected length of stay (ELOS) for $\mathrm{CMG}+2015$. Ottawa: Canadian Institute for Health Information; 2015. Available: https://secure.cihi.ca/estore/productSeries.htm?locale=en \&pc=PCC90 (accessed 2017 Dec. 4)

20. Wodchis WP, Bushmeneva K, Nikitovic M, et al. Guidelines on person-level costing using administrative databases in Ontario. Working Paper Series Vol. 1. Toronto: Health System Performance Research Network; 2013.

21. CMG+ methodology. Ottawa: Canadian Institute for Health Information; 2015. Available: https://secure.cihi.ca/estore/productSeries.htm?locale=en\& pc=PCC358 (accessed 2017 May 10).

22. Hall R, Mondor L, Porter J, et al. Accuracy of administrative data for the coding of acute stroke and TIAs. Can 7 Neurol Sci 2016;43:765-73.

23. Quality-based procedures: clinical handbook for stroke. Toronto: Health Quality Ontario; Ministry of Health and Long-Term Care; 2013.

24. Quality-based procedures: clinical handbook for community-acquired pneumonia. Toronto: Health Quality Ontario; Ministry of Health and Long-Term Care; 2013.

25. Quality-based procedures: clinical handbook for congestive heart failure. Toronto: Health Quality Ontario; Ministry of Health and Long-Term Care; 2013.

26. Quality-based procedures: clinical handbook for chronic obstructive pulmonary disease. Toronto: Health Quality Ontario; Ministry of Health and Long-Term Care; 2013.

27. Kwong JC, Crowcroft NS, Campitelli MA, et al. Ontario Burden of Infectious Disease Study (ONBOIDS): an OAHPP/ICES report. Toronto: Ontario Agency for Health Protection and Promotion/Institute for Clinical Evaluative Sciences; 2010. Available: www.publichealthontario.ca/en/eRepository/ONBOIDS_ EXECUTIVE_SUMMARY.pdf (accessed 2017 Dec. 4).

28. Leading hospitalization costs in acute inpatient facilities in 2012-2013. Ottawa: Canadian Institute for Health Information; 2013. Available: https://www.cihi. ca/en/cad_costingdata_infosheet14_en.pdf (accessed 2017 Dec. 4)

29. McAlister FA, Bakal JA, Majumdar SR, et al. Safely and effectively reducing inpatient length of stay: a controlled study of the General Internal Medicine Care Transformation Initiative. BM7 Qual Saf 2014;23:446-56.

30. McAlister FA, Youngson E, Bakal JA, et al. Physician experience and outcomes among patients admitted to general internal medicine teaching wards. CMAF 2015;187:1041-8

31. Ong M. House staff team workload and organization effects on patient outcomes in an academic general internal medicine inpatient service. Arch Intern Med 2007;167:47-52

32. Kellett J, Deane B. The diagnoses and co-morbidity encountered in the hospital practice of acute internal medicine. Eur 7 Intern Med 2007;18:467-73.

33. Buurman BM, Frenkel WJ, Abu-Hanna A, et al. Acute and chronic diseases as part of multimorbidity in acutely hospitalized older patients. Eur 7 Intern Med 2016;27:68-75.

34. Data quality study of the 2015-2016 Discharge Abstract Database: a focus on hospital harm. Ottawa: Canadian Institute for Health Information; 2016.

Competing interests: Muhammad Mamdani has served on the advisory boards of and reports personal fees from Bristol-Myers Squibb, Eli Lilly and Company, GlaxoSmithKline, Hoffman-La Roche, Novartis, Novo Nordisk, Pfizer and AstraZeneca outside of the submitted work. Irfan Dhalla is Vice-president of Evidence Development and Standards at Health Quality Ontario. Any opinions or conclusions expressed in this publication do not necessarily represent the opinions or conclusions of Health Quality Ontario. No endorsement is intended or should be inferred.

Affiliations: Li Ka Shing Centre for Healthcare Analytics Research and Training (Verma, Mamdani), St. Michael's Hospital; Eliot Phillipson Clinician-Scientist Training Program (Verma), Department of Medicine, University of Toronto; Li Ka Shing Knowledge Institute (Guo, Dhalla, Hwang, Laupacis, Mamdani, Razak), St. Michael's Hospital; Department of Medicine (Kwan), Sinai Health System; Department of Medicine (Kwan, Lapointe-Shaw, Rawal, Razak, Tang, Weinerman), University of Toronto; Division of General Internal Medicine (Rawal), University Health Network; Institute for Better Health (Tang, Reid), Trillium Health Partners; Sunnybrook Health Sciences Centre (Weinerman); University Health Network, Sinai Health System (Cram), University of Toronto; Health Quality Ontario (Dhalla); Sunnybrook Health Sciences Centre (Shadowitz), University of Toronto; Bridgepoint Health (Upshur), University of Toronto, Toronto, Ont.; Harvard Center for Population and Development Studies (Razak), Cambridge, Mass.

Contributors: Amol Verma and Fahad Razak conceived and co-led the study, supervised data collection and designed the analyses. Amol Verma drafted the manuscript. Yishan Guo conducted data analysis and contributed substantially to manuscript revision. Janice Kwan, Lauren Lapointe-Shaw, Shail Rawal, Terence Tang, Adina Weinerman, Peter Cram, Robert Reid and Steven Shadowitz served as site lead investigators, facilitated local data collection, contributed to the study design and contributed substantially to manuscript revision. Irfan Dhalla, Stephen Hwang, Ross Upshur, Andreas Laupacis and Muhammad Mamdani contributed to the study design and data interpretation, and contributed substantially to manuscript revision. All of the authors gave final approval of the version to be published and agreed to be accountable for all aspects of the work.

Funding: The General Medicine Inpatient Initiative (GEMINI) study was supported by grants from Green Shield Canada Foundation and the Division of General Internal Medicine, University of Toronto. Peter Cram is supported by K24 award AR062133 from the National Institute of Arthritis and Musculoskeletal and Skin Diseases, National Institutes of Health.

Acknowledgments: For their contributions to data collection and study design, the authors acknowledge William Coke, Trillium Health Partners, Wanrudee Isaranuwatchai, St. Michael's Hospital and University of Toronto, and Christopher Ducharme, St. Michael's Hospital. The authors thank the Information Technology, Decision Support and Departmental services of each hospital, whose efforts enabled extraction of electronic clinical data.

Supplemental information: For reviewer comments and the original submission of this manuscript, please see www.cmajopen.ca/content/5/4/ E842/suppl/DC1. 